\title{
PREVENTION STRATEGY FOR ANTIMICROBIAL RESISTANCE DEVELOPMENT IN BACTERIA THROUGH MILK AND CONSERVATION OF ANTIBIOTIC SENSITIVITY
}

\author{
T. K. SAR* ${ }^{*}$ R. BURAGOHAIN AND I. SAMANTA ${ }^{1}$ \\ Department of Veterinary Pharmacology and Toxicology \\ West Bengal University of Animal and Fishery Sciences \\ 37, K. B. Sarani, Belgachia, Kolkata - 700037 \\ West Bengal, India
}

\begin{abstract}
Residue of some antibacterial drugs persist at a lower concentration for prolonged time in milk of cows, buffaloes and goats after treatment of bacterial infections by antibacterial drugs following repeated or single dosing. Repeated dosing of antimicrobial agent is required to maintain therapeutic concentration for desirable period to cure mastitis and other bacterial infections. However, prolonged persistence of the antibiotic residue selectively preserves the resistant microorganism which triggers antimicrobial resistance development. Our recommended herbal preparations should be applied in milk producing animals towards production of safe milk as it is consumed by a large population and suckling animals. These herbal preparations have the potential to conserve antibiotic sensitivity which would keep the antibacterial drugs effective towards successful therapy of different bacterial infections in animals and human beings.
\end{abstract}

Key words: Antibiotic residue, Antimicrobial resistance, Dairy animals, Herbal drugs, Persistence

Residue of some antibacterial drugs persist at a lower concentration for prolonged time in milk of cows, buffaloes and goats after treatment of bacterial infections by antibacterial drugs following repeated or even after single dosing (Ismail, 2005; Stolker et al., 2008) which increases the probability of antibiotic resistance development in bacteria. These resistant bacteria are being developed upon exposure to sub MIC (minimum inhibitory concentration) level of antibiotics may spread to different animals as well as humans resulting in public health hazards (Vasavada,1998; Wistrand-Yuen et al., 2018). Sub-lethal levels of $\beta$-lactam antibiotics, aminoglycosides, and fluoroquinolones result in increased

*Corresponding Author

${ }^{1}$ Department of Veterinary Microbiology, WBUAFS, 37, K. B. Sarani, Kolkata - 700037 
mutation frequency in Pseudomonas aeruginosa causing resistance development against these antibiotics (Nair et al., 2013). Methicillin and vancomycin resistant Staphylococcus aureus (Normanno et al., 2007; Sasidharan et al., 2011) oxacillin and penicillin resistant Listeria monocytogenes (Harakeh et al., 2009) and multi drug resistant Listeria species (Rahimi et al., 2010) were detected in milk and milk products. Ampicillin, vancomycin, and ciprofloxacin resistant Escherichia coli, Salmonella spp. and Klebsiella spp. were also isolated from raw milk, pasteurized milk and yogurt samples (Marjan et al., 2014). Administration of antibacterial drugs to dairy animals suffering from chronic mastitis may also lead to lower concentration of antibacterial drugs in milk due to fibrosis (Dash et al., 2019). There are over 264 million dairy cow worldwide, producing nearly 600 million tonnes of milk every year. The average rate of milk yield is 2,200 litres per cow (FAO STAT, 2012). Around $12.5 \%$ of world's cattle population is present in India with a total cow population of 122.9 million and out of which 19.42 million is exotic/crossbred milch cattle (Livestock census, 2007). Occurrence of mastitis in dairy animals stands at first position as mastitis prevalence had been observed to be more than $90 \%$ in crossbred dairy cows (Sharma, 2003). Mastitis is the inflammation of the mammary gland which is manifested by physio-chemical and microbial alterations in the milk with pathological lesions in the udder. The primary reservoir of contagious pathogens is mammary gland whereas contaminated surroundings are one of the main sources of microorganisms causing mastitis (Hillerton and Berry, 2005).
Streptococcus agalactiae, Staphylococcus aureus and Mycoplasma spp. are reported as dominant infecting microorganisms. Streptococci other than Streptococcus agalactiae such as Streptococcus uberis and enterococci are typical environmental pathogens causing mastitis (Kluytmans et al., 1997). The most prevalent causative organism is Staphylococcus aureus that causes acute suppurative, gangrenous, or chronic mastitis. Mastitis generally appears in clinical and sub-clinical forms (Radostits et al., 2000). Incidence of sub-clinical mastitis is 15-40 times higher than clinical mastitis. Staphylococcus aureus is also a source of food borne diseases (FBD) imposing estimated 241,000 illnesses per year in USA (Scallan et al., 2011). FBD involves great economic burden due to lost productivity, health care and management in the United States (Scharff, 2012; ByrdBredbenner et al., 2013). S. aureus produces a variety of toxins namely Staphylococcal enterotoxins (SEA, SEB, SEC, SED, SEE, SEG, SEH, SEI, and SEJ) (Balaban and Rasooly, 2000; Argudín et al., 2010). Pyrogenic toxins are responsible for immune suppression along with nonspecific T-cell proliferation (Le Loir et al., 2003). $\quad S$. aureus is also a common mastitis causing microorganism in goats (De Buyser et al., 1987). SEC was the predominant toxin isolated from Staphylococcal mastitis milk samples from sheep, goats and cattle (Scherrer et al., 2004). The sources of enterotoxin producing $S$. aureus were goat's milk, udder and teats (Valle et al., 1990; Foschino et al., 2002). Six SFD outbreaks occurred in France in 2009 by SEE from soft cheese prepared from unpasteurized milk (Ostyn et al., 2010). 


\section{Public health hazards through milk}

To address the global problem of mastitis and presence of milk antibiotic, some therapeutic strategies have been developed which can be applied in a rational manner in field condition and dairy farms. Antibiotic is commonly employed for treatment of mastitis and the effectiveness of antibacterial drugs can be maximized by maintaining minimum inhibitory concentration (MIC) for a desirable period (Sawant et al., 2005; Cagnardi et al., 2010). Antibacterial drugs are useful to treat the bacterial infection but they cannot protect the glands from tissue damage. Repeated administration of antimicrobial agent is also required to maintain MIC for an adequate period to cure mastitis which is not often cost effective. Besides, the animals sometime suffer from systemic infection due to the spread of the microorganism from the infected mammary gland. Intramammary administration is also adopted mastitis treatment but, intramammary administration of most of the antimicrobial agents was suspected to cause mammary gland tissue damage. The imbalance of innate antioxidant system and reactive oxygen species leads to oxidative stress making the mammary gland more prone to tissue damage that also results in marked reduction in milk production. Persistence of antibacterial drugs in milk enhanced probability of antimicrobial resistance development in bacteria. Milk is a common food item as it is a balanced diet (FAO Statistics Division, 2007). However, prolonged persistence of the antibiotics selectively preserves the resistant microorganism which triggers antimicrobial resistance development. On the other hand, milk is considered as nutrient rich media which acts as favourable environment for growth and multiplication of those resistant microorganisms. The incidence of mastitis was reported in women during lactation which may go up to $33 \%$. Higher incidence of women mastitis had been reported from Australia and the major causative organism was Staphylococcus aureus (Fetherston, 1997). Selection of antimicrobial agent and maintenance of therapeutic concentration are the major challenges in antibiotic therapy of mastitis. New cephalosporins are preferred for mastitis therapy in dairy due to betalactamase resistance, spectrum of activity and lack of toxicity (Mattila-Sandholm et al., 1990). Parenteral administration of ceftriaxone and ceftizoxime has been a common practice for treatment of bacterial infections including mastitis. However, ceftizoxime was excreted for comparatively longer period through milk of cows, goats and buffaloes (Sar et al., 2006; 2008; 2010; 2011 and 2013). Mastitis is still remaining as a costly dreadful disease in livestock in the world due to frequent failure in prevention and treatment. The major reasons are unplanned therapy or lack of strategy for prevention, poor management, unhygienic environment and treatment without proper diagnosis. In many developing and underdeveloped countries, the infrastructures needed for diagnosis of different stages of mastitis are not available. Failure of proper diagnosis many times results in unsuccessful treatment. Even antibiotic sensitivity test is not done in most of the cases, sometimes due to lack of facilities and many times due to severity of the disease giving no scope to wait for antibiotic sensitivity test result. In that situation, veterinarians or medical doctors 
have to administer main drug with supportive drugs empirically. As a result, it leads to aggravation of mastitis cases. In case of dairy animals, milk production is badly affected due to treatment failure. Health of young suckling animals and milk consumers are also compromised. On the other hand, improper and indiscriminate use of antimicrobial drugs associated with their harmful drug interactions result in adverse effects of drugs in mastitis affected animals as well as milk consumers. Another great concern of the present conventional therapy of mastitis is the antimicrobial resistance development in the microorganisms that can cause serious microbial infections in humans especially in children as they consume milk on a regular basis. Long term use of single or multiple antimicrobial (combined) drugs leads to antimicrobial drug residues in milk and dairy products and also causes selection pressure helping the microorganisms to resist these drugs. Sometimes, these resistant microorganisms spread through various routes and jump from one species of animal to another animal species. Animals and humans also suffer from infections of resistant microorganisms due to lack of antibiotic stewardship and antimicrobial drug policy particularly for veterinary drugs in almost all countries. All these problems associated with the present conventional mastitis therapy are imposing threats to public and animal health.

\section{Approaches for conservation of antibiotic sensitivity}

Therefore, new approaches are the needs of the time to address the burning global problem of antibiotic resistant microorganisms spreading through consumption of milk and dairy products. Some supportive herbal therapies developed by our team, can be used as adjunct to antibacterial drugs to protect the animal from oxidative stress, inflammation and related patho-physiological changes. It was found that Oscimum sanctum leaf juice may be useful as supportive therapy to intravenous ceftriaxone for treatment of caprine Staphylococcal chronic mastitis due to its potent bioavailability enhancing and antioxidant properties (Dash et al., 2016). Bauhinia variegata $\mathrm{L}$. bark powder following repeated oral dosing, once daily for 14 days, showed anti fibrotic, antibacterial, anti-inflammatory and antioxidant activities in chronic Stapylococcal mastitis which may be recommended as supportive therapy with antimicrobial drug (Dash et al., 2014). Generally, broad spectrum antibacterial drugs are preferred over narrow spectrum drugs as mastitis is often caused by multiple numbers of organisms. Use of single antibiotic or combination following repeated dosing may result in undesired persistence of antibiotic residues in milk/mammary gland increasing chances of development of antimicrobial resistance and other pathological complexities. A broadspectrum antibiotic i.e. ceftriaxone was reported to be effective in mastitis as a single dose therapy in cows and goats (Sar et al., 2006; 2010). Another antibiotic having structural similarity with ceftriaxone i.e. ceftizoxime was also effective for buffalo mastitis (Kumar et al., 2016). The herbal preparations like Ocimum sanctum (tulsi) herbal extract or Bauhinia variegata (shetkanchan) bark powder can be recommended as supportive therapy with 
single dose of intravenous ceftriaxone/ ceftizoxime in mastitis in cows, buffaloes and goats. When cattle are treated with antibiotics, their milk retains the antibacterial drug residue for a significant time that may be a triggering factor antimicrobial resistance (AMR) development. It was reported that a commercial herbal drug (Fibrosin $\left.{ }^{\circledR}\right)$ when given with antibiotic has the potential to prevent antimicrobial resistance in causative organisms (Sar et al., 2018). Mastitis, a prevalent disease in cows, goats and buffaloes, is not only a major concern for the milk production but also a public health menace. Ceftriaxone gets converted into an active metabolite called ceftizoxime in cows and goats, another third generation cephalosporin that excreted for longer time in their milk. Fibrosin ${ }^{\circledR}$ is recommended to increase the bioavailability of ceftizoxime (metabolite) in milk and also to eliminate it at a much faster rate compared to control goats that did not receive the commercial herbal drug (Sar et al., 2018).

\section{REFERENCES}

Argudín MÁ, Mendoza MC and Rodicio MR, 2010. Food poisoning and Staphylococcus aureus enterotoxins. Toxins (Basel), 2(7): 1751-1773

Balaban N and Rasooly A, 2000. Staphylococcal enterotoxins. Int J Food Microbiol, 61(1): $1-10$

Byrd-Bredbenner C, Berning J, Martin-Biggers J and Quick V, 2013. Food safety in home kitchens: a synthesis of the literature. Int J Environ Res Public Health, 10(9): 40604085
Therefore, our recommended herbal supportive therapies should be applied in milk producing animals towards production of safe milk as it is consumed by a large population in the world. These herbal preparations returned milk alkaline phosphatase and catalase activity in mastitic goats to normal level and increased lactoperoxidase (antimicrobial system in milk) activity significantly (Sar et al., 2012; Dash et al., 2014; 2016).

\section{Conclusion}

Therefore, the commercial herbal drug and other mentioned herbal preparations are recommended to decrease persistence of these cephalosporins like ceftriaxone and ceftizoxime following their parenteral administration. These herbal preparations can conserve antibiotic sensitivity which would keep the antibacterial drugs effective towards successful therapy of different bacterial infections as these drugs are used both in humans and animals.

Cagnardi P, Villa P, Gallo M, Locatelli C, Carli S et al., 2010. Cefoperazone sodium preparation behaviour after intramammary administration in healthy and infected cows. J Dairy Sci, 93(9): 4105-4110

Dash JR, Sar TK, Buragohain R, Samanta I and Nanotkar R, 2019. Evaluation of fibrolytic effect of Bauhinia purpurea L. Clinical Cancer Drugs, 6(1): 21-32

Dash JR, Sar TK, Samanta I and Mandal TK, 2016. Effects of herbal extract of Ocimum sanctum as supportive therapy with 
intravenous ceftriaxone in experimentally induced Staphylococcal chronic mastitis in goat. Small Ruminant Res, 137: 1-8

Dash JR, Sar TK, Samanta I, Pal S, Khan M et al., 2014. Efficacy evaluation of Bauhinia variegata L. stem bark powder as adjunct therapy in chronic Staphylococcus aureus mastitis in goat. Pharmacogn Mag, 10(Suppl3): 512-518

De Buyser ML, Dilasser F, Hummel R and Bergdoll MS, 1987. Enterotoxin and toxic shock syndrome toxin-1 production by Staphylococci isolated from goat's milk. Int J Food Microbiol, 5(4): 301-309

FAO, 2007. FAO STAT Statistic database agriculture, Rome. Availlable in http:// faostat.fao.org/faostat/ collection

FAO, 2012. FAO STAT Statistic database agriculture, Rome. Availlable in http:// faostat.fao.org/faostat/ collection

Fetherston C, 1997. Management of lactation mastitis in a Western Australian cohort. Breastfeed Rev, 5(2): 13-19

Foschino R, Invernizzi A, Barucco R and Stradiotto K, 2002. Microbial composition including the incidence of pathogens, of goat milk from the Bergamo region of Italy during a lactation year. J Dairy Res, 69(2): 213-225

Harakeh S, Saleh I, Zouhairi O, Baydoun E and Barbour E, 2009. Antimicrobial resistance of Listeria monocytogenes isolated from dairy-based food products. Sci Total Environ, 407(13): 4022-4027

Hillerton JE and Berry EA, 2005.Treating mastitis in the cow-a tradition or an archaism. J Appl Microbiol, 98(6): 12501255

Ismail MM, 2005. Pharmacokinetics, urinary and mammary excretion of ceftriaxone in lactating goat. J Vet Med A, 52: 354-358

Kluytmans J, Van Belkum A and Verbrugh H, 1997. Nasal carriage of Staphylococcus aureus: epidemiology, underlying mechanisms, and associated risks. Clin Microbiol Rev, 10(3): 505-520

Kumar R, Sar TK, Patra PH, Samanta I, Mishra A et al., 2016. Disposition kinetics of ceftizoxime in acute mastitis in Murrah buffaloes. Indian J Anim Sci, 86(2): 140142

Le Loir Y, Baron F and Gautier M, 2003. Staphylococcus aureus and food poisoning. Genet Mol Res, 2(1): 63-76

Marjan S, Das KK, Munshi SK and Noor R, 2014. Drug-resistant bacterial pathogens in milk and some milk products. Nutr Food Sci, 44: 241-248

Mattila-Sandholm T, Alivehmas T, Kaartinen L and Honkanen-Buzalski T, 1990. Growth characteristics of Staphylococcus aureus and Escherichia coli in whey from sequentially infected milk. Acta Vet Scand, 31(2): 169-174

Nair CG, Chao C, Ryall B and Williams HD, 2013. Sub lethal concentrations of antibiotics increase mutation frequency in the cystic fibrosis pathogen Pseudomonas aeruginosa. Lett Appl Microbiol, 56(2): 149-154

Normanno G, La Salandra G, Dambrosio A, 
Quaglia NC, Corrente M et al., 2007. Occurrence, characterization and antimicrobial resistance of enterotoxigenic Staphylococcus aureus isolated from meat and dairy products. Int J Food Microbiol, 115(3): 290-296

Ostyn A, De Buyser ML, Guillier F, Groult J, Felix B et al., 2010. First evidence of a food poisoning outbreak due to Staphylococcal enterotoxin type E, France, 2009. Euro Surveill, 15(13) pii: 19528

Radostits OM, Gay C, Blood DC, Hinchcliff K and Constabl P, 2000. Veterinary Medicine: A Text Book of Disease of Cattle, Sheep, Pigs, Goats, and Horses $\left(9^{\text {th }}\right.$ edn.). W.B. Saunders Company Ltd, Ballier, Tindall, London, pp674-762

Rahimi E, Ameri $\mathrm{M}$ and Momtaz $\mathrm{H}$, 2010. Prevalence and antimicrobial resistance of Listeria species isolated from milk and dairy products in Iran. Food Control, 21(11): 1448-1452

Sar TK, Mandal TK, Das SK, Chakraborty AK and Bhattacharyya A, 2006. Pharmacokinetics of ceftriaxone in healthy and mastitic goats with special reference to its interaction with polyherbal drug (Fibrosin®). Int J Appl Res Vet Med, 4(2): 142-154

Sar TK, Mandal TK, Samanta I, Rahaman A and Chakraborty AK, 2010. Determination of ceftriaxone in plasma and ceftizoxime in milk of mastitic cows following single dose intravenous administration. Indian J Anim Sci, 80(12): 1182-1184

Sar TK, Mandal TK, Samanta I, Rahaman A and
Chakraborty K, 2010. Determination of ceftriaxone in plasma and ceftizoxime in milk of mastitic cows following single dose intravenous administration. Indian J Anim Res, 80(12): 1182-1184

Sar TK, Patra AK, Samanta I and Mandal TK, 2015. Protective effect of a potential polyherbal drug on mammary tissue damage caused by intramammary administration of antibiotic by producing antioxidant action. Indian J Anim Hlth, 54(1): 35-42

Sar TK, Samanta I, Patra PH and Mandal TK, 2012. Effect of combined therapy of intravenous ceftriaxone and oral polyherbal drug on milk enzyme activity in healthy and mastitic goats. Applied Biological Research, 14(1): 95-99

Sar TK, Mandal TK, Das SK and Chakraborty AK, 2008. Pharmacokinetics of ceftriaxone in carbontetrachloride-induced hepatopathic and uranyl nitrate-induced nephropathic goats following single dose intravenous administration. Drug Metab Lett, 2(1): 23-28

Sasidharan S, Prema B and Latha LY, 2011. Antimicrobial drug resistance of Staphylococcus aureus in dairy products. Asian Pac J Trop Biomed, 1(2): 130-132

Sawant AA, Sordillo LM and Jayarao BM, 2005. A survey on antibiotic usage in dairy herds in Pennsylvania. J Dairy Sci, 88(8): 2991-2999

Scallan E, Hoekstra RM, Angulo FJ, Tauxe RV, Widdowson MA et al., 2011. Food borne illness acquired in the United States-major pathogens. Emerg Infect Dis, 17(1): 7-15 
Scharff RL, 2012. Economic burden from health losses due to food borne illness in the United States. J Food Prot, 75(1): 123131

Scherrer D, Corti S, Muehlherr JE, Zweifel C and Stephan R, 2004. Phenotypic and genotypic characteristics of Staphylococcus aureus isolates from raw bulk-tank milk samples of goats and sheep. Vet Microbiol, 101(2): 101-107

Sharma N, 2003. Epidemiological investigation on sub clinical mastitis in dairy animals: Role of vitamin E and selenium supplementation on its control in cattle. M.V.Sc. thesis, submitted to I.G.K.V.V, Raipur, Chhattisgarh, India
Stolker AAM, Rutgers P, Oosterink E, Lasaroms JJP, Peters RJB et al., 2008. Comprehensive screening and quantification of veterinary drugs in milk using UPLC-ToF-MS. Anal Bioanal Chem, 391: 2309-2322

Valle J, Gomez-Lucia E, Piriz S, Goyache J, Orden JA et al., 1990. Enterotoxin production by Staphylococci isolated from healthy goats. Appl Environ. Microbiol, 56(5): 1323-1326

Vasavada, 1988. Public health aspects of raw goat milk. Dairy Goat J, 64: 226-227

Wistrand-Yuen E, Knopp M, Hjort K, Koskiniemi S, Berg OG et al., 2018. Evolution of highlevel resistance during low-level antibiotic exposure. Nat Commun, 9: 1599, doi:10.1038/s41467-018-04059-1 